\title{
Intuitionistic Fuzzy Equipotent Sublattices of Lattice Ordered Groups with Respect to S-Norms
}

\author{
Dr. M. Marudai \\ Associate Professor \\ Department of Mathematics \\ Bharathidasan University \\ Tiruchirappalli - 24, Tamilnadu. India
}

\author{
V. Rajendran \\ Research Scholar \\ Department of Mathematics \\ Bharathidasan University \\ Tiruchirappalli - 24, Tamilnadu. India
}

\begin{abstract}
In this paper, we introduce the notion of intuitionistic fuzzy equipotent lattice in a fuzzy lattice and then some basic properties are investigated. Characterization of intuitionistic fuzzy equipotent lattices are given. Using a collection of lattices, an intuitionistic fuzzy equipotent lattice is established. The notion of fuzzy equipotent lattice relation on the family of all intuitionistic fuzzy sub lattices of $\mathrm{L}$ are discussed upper and lower level sets of fuzzy equipotent lattices are studied.
\end{abstract}

Key Words : Fuzzy lattice, Fuzzy equipotent Lattice, level cut, intuitionistic fuzzy equipotent sub lattice, Homomorphism.

\section{INTRODUCTION}

The theory of fuzzy sets proposed by L.A. Zedeh [27] in 1965, has achieved a great success in various fields. After that time, some author's [17, 21,25] applied this concepts to groups and rings theory. With the research of fuzzy sets, in 1986, K. Atanassov [1] presented intuitionistic fuzzy sets which are very effective to

deal with vagueness. The concept of the intuitionistic fuzzy sets is a generalization of one of the fuzzy sets. Recently Coker and his colleagues [8,9] and Lee [16] introduce the concept of intuitionistic fuzzy topological spaces using intuitionistic fuzzy sets and investigated some of its properties. In 1989, Biswas [6] introduced the concept of intuitionistic fuzzy subgroups and studied some of its properties.

In 2003 Banerjee and Basnet [5] investigated intuitionistic fuzzy subgroups and intuitionistic fuzzy ideals using intuitionistic fuzzy sets. Also Hur and his colleagues [12, 13, 14, 15] studied various properties of intuitionistic fuzzy subgroupoids, intuitionistic fuzzy subrings and intuitionistic fuzzy topological groups. In particular Bustince and Burillo [7] introduce the concept of intuitionistic fuzzy relations and investigated some of its propreties and Yon and Kim [26] introduced the notion of intuitionistic fuzzy sublattices, filters and ideals. In a series of papers $[2,3,4]$ various sub lattices of the lattice L of all fuzzy groups of the group $\mathrm{G}$ are constructed and examined. In papers $[23,24]$ studied the rough sets corresponding to an ideals of a lattice and introduced rough sub lattice and intuitionistic fuzzy sublatices. N. Ajmal and K.V. Thomas initated such types of study in the year 1994. it was latter independently established by $\mathrm{N}$. Ajmal that the set of all fuzzy normal sub groups of a group constitute a sub lattice of the lattice of all subgroups and is modular. Nanda. S [20] proposed the notice of fuzzy lattice using the concept of fuzzy partial ordering. More recently in the notion of set product is discussed in details and in the lattice theoretical aspects of fuzzy sub groups and fuzzy normal sub groups are explored.

G.S.V. Satya Saibaba [22] initiated the study of L-fuzzy lattice ordered groups and introducing the notion L fuzzy sub - 1 groups. J.A. Goguen [10] replaced the valuation set $[0,1]$ by means of a complete lattice in an attempt to make a generalized study of fuzzy set theory by studying L-fuzzy sets.

In this paper, we investigate intuitionistic fuzzy equipotent lattice, upper and lower level sets and characterization of intuitionistic fuzzy equipotent lattices. The notion of fuzzy equipotent lattice relation on the family of all intuitionistic fuzzy sub lattices of $\mathrm{L}$ are discussed.

\section{PRELIMINARIES}

Definition 2.1 : A mapping $\mu: X \rightarrow[0,1]$, where $X$ is an arbitrary nom-empty set and is called fuzzy set in X.

Definition 2.2 : Let $X$ be a non empty set. An intuitionistic fuzzy set (IFS) $A$ of $X$ is an object of the following form $A=$ $\left\{\left(\mathrm{x}, \mu_{\mathrm{A}}(\mathrm{x}), \gamma_{\mathrm{A}}(\mathrm{x})\right) / \mathrm{x} \in \mathrm{X}\right\}$. Where $\mu_{\mathrm{A}}: \mathrm{X} \rightarrow[0,1]$ and $\gamma_{\mathrm{A}}: X \rightarrow[0,1]$ defined the degree of membership and the degree of non membership of the element $x \in X$,

$\leq \mu_{\mathrm{A}}(\mathrm{x})+\gamma_{\mathrm{A}}(\mathrm{x}) \leq 1$

Definition 2.3 : A Lattice ordered group (LG) is a system $\mathrm{G}=$ $(\mathrm{G},+, \leq)$

Where

(i) $(\mathrm{G},+)$ is a group

(ii) $\quad(\mathrm{G},$.$) is a lattice$

(iii) $\quad \mathrm{x}+\mathrm{a}+\mathrm{y}=\mathrm{b}+\mathrm{y} \rightarrow \mathrm{G}(\mathrm{x}) \leq \max \{\mathrm{G}(\mathrm{a})$, $\mathrm{G}(\mathrm{b})\}$, for all $\mathrm{x}, \mathrm{y}, \mathrm{a}, \mathrm{b} \in \mathrm{G}$.

Definition 2.4 : Let $\mu$ be a fuzzy lattice ordered group of G. A map $A: X \rightarrow G$ is called a fuzzy lattice if

(i) $\quad \mathrm{A}(\mathrm{x}+\mathrm{y}) \geq \min \{\mathrm{A}(\mathrm{x}), \mathrm{A}(\mathrm{y})\}$

(ii) $\quad \mathrm{A}(-\mathrm{x}) \quad \geq \mathrm{A}(\mathrm{x})$

(iii) $\mathrm{A}(\mathrm{x} \vee \mathrm{y}) \geq \min \{\mathrm{A}(\mathrm{x}), \mathrm{A}(\mathrm{y})\}$

(iv) $\mathrm{A}(\mathrm{x} \Lambda \mathrm{y}) \geq \min \{\mathrm{A}(\mathrm{x}), \mathrm{A}(\mathrm{y})\}, \quad$ for all $\mathrm{x}, \mathrm{y} \in \mathrm{G}$.

Definition 2.5 : A lattice L is called a fuzzy complete lattice if every complete lattice is a poset, in which its subset has infirmum and supremum. 
Definition 2.6 : By S-norm, we mean a function $\mathrm{S}:[0,1]$ x $[0$, $1] \rightarrow[0,1]$ satisfying the following conditions.

(i) $\mathrm{S}(\mathrm{x}, 0)=\mathrm{x}$

(ii) $\mathrm{S}(\mathrm{x}, \mathrm{y})=\mathrm{S}(\mathrm{y}, \mathrm{x})$

(iii) $y \leq z \Rightarrow S(x, y) \leq S(x, z)$

(iv) $S(S(x, y), z)=S(x, S(y, z))$, for all $x, y, z \in[0,1]$

Definition 2.7 : A fuzzy lattice $\mathrm{L}$ under $\mu$ is called equipotent fuzzy lattice if

(1) $\mu(\mathrm{x}+\mathrm{y}) \geq \mathrm{T}\{\mu(\mathrm{x}), \mu(\mathrm{y})\}$

(ii) $) \mu(-x) \geq \mu(x)$

(uil) $\mu(x \vee y) \geq T\{\mu(x), \mu(y)\}$, for all $x, \quad y \in L$

Definition 2.8 : Let $\mathrm{I}: \mathrm{X} \rightarrow \mathrm{L}$ is called intuitionistic fuzzy lattice over $\mathrm{L}$ if

(i)

$\mathrm{I}(\mathrm{x}+\mathrm{y}) \geq \mathrm{T}\{\mathrm{I}(\mathrm{x}), \mathrm{I}(\mathrm{y})\}$

$\mathrm{I}(-\mathrm{x}) \geq \mathrm{I}(\mathrm{x})$

$\mathrm{I}(\mathrm{x}$ V y) $\geq \mathrm{T}\{\mathrm{I}(\mathrm{x}), \mathrm{I}(\mathrm{y})\}$

$\mathrm{I}(\mathrm{x} \Lambda \mathrm{y}) \geq \mathrm{T}\{\mathrm{I}(\mathrm{x}), \mathrm{I}(\mathrm{y})\}$ Where $\mathrm{I}=(\mu, \gamma)$. For all $\mathrm{x}, \mathrm{y} \in \mathrm{L}$.

Definition 2.9 : An intuitionistic fuzzy set A in L is called intuitionistic fuzzy equipotent sublatice of $\mathrm{L}$ if, the following conditions are satisfied.

(i) $\mathrm{I}_{\mathrm{A}}(\mathrm{x}+\mathrm{y}) \geq \mathrm{T}\left\{\mathrm{I}_{\mathrm{A}}(\mathrm{x}), \mathrm{I}_{\mathrm{A}}(\mathrm{y})\right\}$

(ii) $\mathrm{I}_{\mathrm{A}}(-\mathrm{x}) \geq \mathrm{I}_{\mathrm{A}}(\mathrm{x})$

(iii) $\mathrm{I}_{\mathrm{A}}(\mathrm{x} * \mathrm{y}) \geq \max \left\{\min \left\{\mathrm{I}_{\mathrm{A}}(\mathrm{x}), \mathrm{I}_{\mathrm{A}}(\mathrm{y})\right\}\right\}$, for all $\mathrm{x}, \mathrm{y} \in \mathrm{L}$. operations.

Here $*$ represents the combination of meet and joint

Definition 2.10 : Let $\mu$ be a fuzzy subset of a set $L$ and $t \in[0$, 1]. Then the set $\mu_{t}=\{x \in L / \mu(x) \geq t\}$ is called level sub set of $\mu$.

Definition 2.11 : An intuitionistic fuzzy equipotent lattice $A$ is said to be self-distributive intuitionistic fuzzy set in $\mathrm{L}$ and $\mathrm{I}_{\mathrm{A}}$ is fuzzy equipotent lattice then $\mathrm{I}_{\mathrm{a}}^{\mathrm{b}}(\mathrm{x})=\mathrm{a}^{\mathrm{b}} \mathrm{I}(\mathrm{x})$, for any $\mathrm{a}, \mathrm{b} \in \mathrm{L}$.

Definition 2.12 : Let $\mathrm{f}: \mathrm{L} \rightarrow \mathrm{L}^{\prime}$ be a lattice homomorphism. $\mathrm{f}$ is fuzzy lattice homomorphism if

$f(x+y)=f(x)+f(y)$, for all $x, y \in L$.

Definition 2.13 : A fuzzy set $S$ dominates $S^{*}$ if $S^{*} \supseteq S$. (ie) $S^{*}$ dominates $\mathrm{S}$.

Definition 2.14 : Let $\mu$ and $\gamma$ be two fuzzy equipotent lattice. Then fuzzy equipotent class is defined as

$[\mu \cdot \gamma]_{S^{*}}(\mathrm{x})=\max \left\{\mu_{\mathrm{s}^{*}}(\mathrm{x}), \gamma_{\mathrm{s}^{*}}(\mathrm{x})\right\}$

$$
=\max \left\{s^{*} \mu(x), s^{*} \gamma(x)\right\} \quad \text { for al } x, y \in L \text {. }
$$

\section{PROPERTIES OF INTUITIONISTIC FUZZY EQUIPOTENT SUBLATTICES}

Proposition 3.1 : If an intuitionistic fuzzy set $\mathrm{A}$ in $\mathrm{L}$ is a intuitionistic fuzzy equipotent sub lattice of $\mathrm{L}$ then so, is $\mathrm{A}=\left\{\left\{\left(\mathrm{x}, \mu_{\mathrm{A}}(\mathrm{x}), 1-\mu_{\mathrm{A}}(\mathrm{x})\right\} / \mathrm{x} \in \mathrm{L}\right\}\right.$
Proof : Suppose A is an intuitionistic fuzzy equipotent lattice of L. Then for any $\mathrm{x}, \mathrm{y} \in \mathrm{A}, \mathrm{x}+\mathrm{y} \in \mathrm{A}$ and $\mathrm{x} * \mathrm{y} \in \mathrm{A}$.

Then

$$
\mu_{\mathrm{A}}(\mathrm{x})=\mu_{\mathrm{A}}(\mathrm{y})=1 \text { and } 1-\gamma_{\mathrm{A}}(\mathrm{x})=1-\gamma_{\mathrm{A}}(\mathrm{y})=0
$$

$\mu_{\mathrm{A}}(\mathrm{x}+\mathrm{y})=\mathrm{T}\left\{\mu_{\mathrm{A}}(\mathrm{x}), \mu_{\mathrm{A}}(\mathrm{y})\right\}$

$\mu_{\mathrm{A}}(\mathrm{x} * \mathrm{y})=\max \left\{\min \left\{\mu_{\mathrm{A}}(\mathrm{x}), \mu_{\mathrm{A}}(\mathrm{y})\right\}\right\}$ and

$\left(1-\gamma_{\mathrm{A}}\right)(\mathrm{x}+\mathrm{y})=\mathrm{S}\left\{\left(1-\gamma_{\mathrm{A}}\right)(\mathrm{x}),\left(1-\gamma_{\mathrm{A}}\right)(\mathrm{y})\right\}$

$\left(1-\gamma_{\mathrm{A}}\right)(\mathrm{x} * \mathrm{y})=\min \left\{\max \left\{\left(1-\gamma_{\mathrm{A}}\right)(\mathrm{x}),\left(1-\gamma_{\mathrm{A}}\right)(\mathrm{y})\right\}\right\}$

Suppose $\mathrm{x}, \mathrm{y} \in \mathrm{L}$ and at least one of them say $\mathrm{y} \notin \mathrm{A}$, then $\mu_{\mathrm{A}}(\mathrm{y})=0,\left(1-\gamma_{\mathrm{A}}\right)(\mathrm{y})=1, \gamma_{\mathrm{A}}(\mathrm{x}) \Lambda \gamma_{\mathrm{A}}(\mathrm{y})=0$ $\left(1-\gamma_{\mathrm{A}}\right)(\mathrm{x}) \mathrm{V}\left(1-\gamma_{\mathrm{A}}\right)(\mathrm{y})=1$

$\mu_{\mathrm{A}}(\mathrm{x}+\mathrm{y}) \geq \mathrm{T}\left\{\mu_{\mathrm{A}}(\mathrm{x}), \mu_{\mathrm{A}}(\mathrm{y})\right\}$ and $\quad \mu_{\mathrm{A}}(\mathrm{x} * \mathrm{y})=\max \{\min$ $\left.\left\{\mu_{\mathrm{A}}(\mathrm{x}), \mu_{\mathrm{A}}(\mathrm{y})\right\}\right\}$

$\left(1-\gamma_{\mathrm{A}}\right)(\mathrm{x}+\mathrm{y}) \leq \mathrm{S}\left\{\left(1-\gamma_{\mathrm{A}}\right)(\mathrm{x}),\left(1-\gamma_{\mathrm{A}}\right)(\mathrm{y})\right\}$ and

$\left(1-\gamma_{\mathrm{A}}\right)(\mathrm{x} * \mathrm{y}) \leq \min \left\{\max \left\{\left(1-\gamma_{\mathrm{A}}\right)(\mathrm{x}),\left(1-\gamma_{\mathrm{A}}\right)(\mathrm{y})\right\}\right\}$

Thus $\left(\mu_{\mathrm{A}}, 1-\gamma_{\mathrm{A}}\right)$ satisfies the properties of intuitionistic fuzzy equipotent lattice.

Conversely,

Suppose $\left(\mu_{\mathrm{A}}, 1-\gamma_{\mathrm{A}}\right)$ is fuzzy equipotent lattice of $\mathrm{L}$.

Let $\mathrm{x}, \mathrm{y} \in \mathrm{A} . \quad \mu_{\mathrm{A}}(\mathrm{x})=\mu_{\mathrm{A}}(\mathrm{y})=1, \quad \mathrm{~T}\left\{\mu_{\mathrm{A}}(\mathrm{x}), \mu_{\mathrm{A}}(\mathrm{y})\right\}$ $=1$

But, both $\mu_{\mathrm{A}}(\mathrm{x}+\mathrm{y})$ and $\mu_{\mathrm{A}}(\mathrm{x} * \mathrm{y}) \geq \mathrm{T}\left\{\mu_{\mathrm{A}}(\mathrm{x}), \mu_{\mathrm{A}}(\mathrm{y})\right\}$

Thus, A is intuitionistic fuzzy equipotent lattice of $\mathrm{L}$.

Proposition 3.2 : If an intuitionistic fuzzy set $\mathrm{A}$ in $\mathrm{L}$ is intuitionistic fuzzy equipotent sub lattice of $L$ if $\mu_{A}$ and $\gamma^{C}{ }_{A}$ are fuzzy lattice of L.

Proof : Let $I_{A}=\left(\mu_{A}, \gamma_{A}\right)$ be an intuitionistic fuzzy equipotent lattice of $\mathrm{L}$. Then obviously $\mu_{\mathrm{A}}$ is fuzzy equipotent lattice of $\mathrm{L}$. Let $x, y \in$ L. then,

$$
\begin{aligned}
&(\text { IFEPL1 }) \gamma_{\mathrm{A}}^{\mathrm{C}}(\mathrm{x}+\mathrm{y})=1-\gamma_{\mathrm{A}}(\mathrm{x}+\mathrm{y}) \\
& \geq 1-\max \left\{\gamma_{\mathrm{A}}(\mathrm{x}), \gamma_{\mathrm{A}}(\mathrm{y})\right\} \\
& \geq \mathrm{T}\left\{\gamma_{\mathrm{A}}^{\mathrm{C}}(\mathrm{x}), \gamma_{\mathrm{A}}^{\mathrm{C}}(\mathrm{y})\right\}
\end{aligned}
$$

$$
\begin{aligned}
(\operatorname{IFEPL} 2) \gamma_{\mathrm{A}}^{\mathrm{C}}(-\mathrm{x})= & 1-\gamma_{\mathrm{A}}(-\mathrm{x}) \\
& \geq 1-\gamma_{\mathrm{A}}(\mathrm{x}) \\
& =\gamma_{\mathrm{A}}^{\mathrm{C}}(\mathrm{x})
\end{aligned}
$$

(IFEPL3) $\gamma_{\mathrm{A}}^{\mathrm{C}}(\mathrm{x} * \mathrm{y}) \quad=1-\gamma_{\mathrm{A}}(\mathrm{x} * \mathrm{y})$

$\leq 1-\min \left\{\max \left\{\gamma_{\mathrm{A}}(\mathrm{x}), \gamma_{\mathrm{A}}(\mathrm{y})\right\}\right\}$

$=\max \left\{\min \left\{1-\gamma_{\mathrm{A}}(\mathrm{x}), 1-\gamma_{\mathrm{A}}(\mathrm{y})\right\}\right\}$

$=\max \left\{\min \left\{\gamma_{\mathrm{A}}^{\mathrm{C}}(\mathrm{x}), \gamma_{\mathrm{A}}^{\mathrm{C}}(\mathrm{y})\right\}\right\}$

of L. 
Conversely, suppose that $\mu_{\mathrm{A}}$ and $\gamma_{\mathrm{A}}^{\mathrm{C}}$ are intuitionistic fuzzy equipotent lattice of L. Let $\mathrm{x}, \mathrm{y} \in \mathrm{L}$.

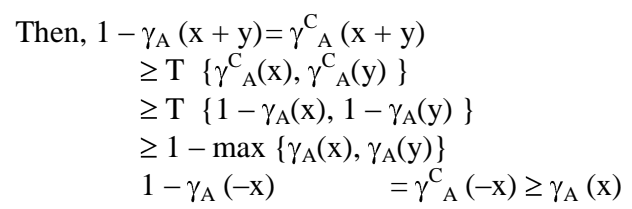

Which imply $\gamma_{\mathrm{A}}(\mathrm{x}+\mathrm{y}) \leq \mathrm{S}\left\{\gamma_{\mathrm{A}}(\mathrm{x}), \gamma_{\mathrm{A}}(\mathrm{y})\right\}$

$$
\gamma_{\mathrm{A}}(\mathrm{x}) \leq \gamma_{\mathrm{A}}(\mathrm{y})
$$

Finally, for any $\mathrm{x}, \mathrm{y} \in \mathrm{L}$,

$$
1-\gamma_{\mathrm{A}}(\mathrm{x} * \mathrm{y}) \quad=\gamma^{\mathrm{C}} \mathrm{A}(\mathrm{x} * \mathrm{y})
$$$$
\geq \max \left\{\min \left\{\gamma_{\mathrm{A}}^{\mathrm{C}}(\mathrm{x}), \gamma_{\mathrm{A}}^{\mathrm{C}}(\mathrm{y})\right\}\right\}
$$

$\geq \min \left\{\max \left\{1-\gamma_{\mathrm{A}}(\mathrm{x}), 1-\gamma(\mathrm{y})\right\}\right\}$

This completes the proof.

Proposition 3.3 : For any $t \in[0,1]$, the maps $U_{t}$ and $V_{t}$ are surjective from $\mathrm{F}(\mathrm{L})$ to $\mathrm{I}(\mathrm{L}) \mathrm{U}[0,1]$. Moreover the quotient sets $\mathrm{F}(\mathrm{L}) / \sim \mu$ and $\mathrm{F}(\mathrm{L}) / \sim \gamma$ are equipotent to $\mathrm{I}(\mathrm{L}) \mathrm{U}\{0\}$.

\section{Proof :}

Let $\mathrm{t} \in[0,1]$. Note that $0 \sim=[0,1]$ proof is in $\mathrm{F}(\mathrm{L})$. Where 0 and 1 are fuzzy sets in $L$ defined by $0(x)=0$ and $1(x)=$ 1 for all $\mathrm{x} \in \mathrm{L}$ obviously.

$\mathrm{f}_{\mathrm{t}}(0 \sim)=\mathrm{U}(0 ; \mathrm{t})=\phi=\mathrm{L}(1 ; \mathrm{t})=\mathrm{g}_{\mathrm{t}}(0 \sim)$

Let $\mathrm{J}(\neq \phi) \in \mathrm{I}(\mathrm{L})$. For $\mathrm{J} \sim=\left(\mathrm{X}_{\mathrm{J}}, \overline{\mathrm{X}}_{\mathrm{J}}\right) \in \mathrm{F}(\mathrm{L})$,

We have $\mathrm{f}_{\mathrm{t}}(\mathrm{J} \sim) \quad=\mathrm{U}\left(\mathrm{X}_{\mathrm{J}} ; \mathrm{t}\right)=\mathrm{J}$

Hence $f_{t}$ and $g_{t}$ are surjective.

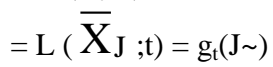

Let $\mathrm{f}_{\mathrm{t}} *$ be a map from $\mathrm{F}(\mathrm{L}) / \sim \mu$ to $\mathrm{I}(\mathrm{L}) \mathrm{U}\{\phi\}$ defined by $\mathrm{f}_{\mathrm{t}} *\left(\left[\mathrm{I}_{\mathrm{A}}\right]_{\mu}\right)=\mathrm{f}_{\mathrm{t}}\left(\mathrm{I}_{\mathrm{A}}\right)$.

Assume that $U\left(\mu_{A} ; t\right)=U\left(\mu_{B} ; t\right)$ and $L\left(\gamma_{A} ; t\right)=L\left(\gamma_{B} ; t\right)$ for $\mathrm{A}, \mathrm{B}$ is $\mathrm{F}(\mathrm{L})$. $\left[\mathrm{I}_{\mathrm{B}}\right] \gamma$.

Then $\mathrm{A} \sim \mu \mathrm{B}$ and $\mathrm{A} \sim \gamma \mathrm{B}$, and hence $\left[\mathrm{I}_{\mathrm{A}}\right] \mu=\left[\mathrm{I}_{\mathrm{B}}\right] \mu,\left[\mathrm{I}_{\mathrm{A}}\right] \gamma=$

Therefore the maps $\mathrm{f}_{\mathrm{t}} *$ and $\mathrm{g}_{\mathrm{t}} *$ are injective.

Now let $\mathrm{J}(\neq \phi) \in \mathrm{I}(\mathrm{L})$.

For $\mathrm{J} \sim=\left(\mathrm{X}_{\mathrm{J}}, \overline{\mathrm{X}}_{\mathrm{J}}\right) \in \mathrm{F}(\mathrm{L})$, we have

$\mathrm{f}_{\mathrm{t}} *\left([\mathrm{~J} \sim]_{\mu}\right)=\mathrm{f}_{\mathrm{t}}(\mathrm{J} \sim)=\mathrm{g}_{\mathrm{t}}\left([\mathrm{J} \sim]_{\gamma}\right)$.

Finally, for $0 \sim=[0,1] \in \mathrm{F}(\mathrm{L})$, we get

$\mathrm{f}_{\mathrm{t}} *\left([0 \sim]_{\mu}\right) \quad=\mathrm{f}_{\mathrm{t}}(0 \sim)=\mathrm{U}(0 ; \mathrm{t})=\phi=\mathrm{L}(1 ; \mathrm{t})$ $=\mathrm{g}_{\mathrm{t}}(0 \sim)=\mathrm{g}_{\mathrm{t}}\left([0 \sim]_{\gamma}\right)$.

This shows that $\mathrm{f}_{\mathrm{t}}^{*}$ and $\mathrm{g}_{\mathrm{t}}{ }^{*}$ are surjective.

Proposition 3.4 : Let $\left\{\mathrm{M}_{\mathrm{t}} / \mathrm{t} \in \mathrm{A} \subseteq[0,1]\right\}$ be a collection of equipotent lattices of $\mathrm{L}$ such that

(i) $\mathrm{J}=\mathrm{U} \quad \mathrm{M}_{\mathrm{t}}$ $\mathrm{t} \in \Lambda$

(ii) For any s.t. $\in \Lambda, S>$ t if and only if $\mathrm{M}_{\mathrm{S}} \subseteq \mathrm{M}_{\mathrm{t}}$.
Proof : Let $\left\{\mathrm{M}_{\mathrm{t}} / \mathrm{t} \in \mathrm{A} \subseteq[0,1]\right\}$ be a collection of fuzzy equipotent lattices of $\mathrm{L}$.

We consider the following two cases.

(i) $\mathrm{S}=\sup \{\mathrm{t} \in \Lambda / \mathrm{t}<\mathrm{s}\}$ and

(ii) $\mathrm{S} \neq \sup \{\mathrm{t} \in \Lambda / \mathrm{t}<\mathrm{s}\}$

Case (i) implies that

$\mathrm{x} \in \mathrm{I}_{\mathrm{S}} \Leftrightarrow \mathrm{x} \in \mathrm{M}_{\mathrm{t}}$ for all $\mathrm{t}<\mathrm{S}$. $\Leftrightarrow \mathrm{x} \in \cap \mathrm{M}_{\mathrm{t}}$ when $\mathrm{t}<\mathrm{p}$

$I_{S}=\cap M_{t}$ which is a lattice of $L$. $\mathrm{t}<\mathrm{p}$

For the case (ii), there exists $\in>0$ such that $(\mathrm{S}-\in, \mathrm{S}) \cap \Lambda=\phi$.

We claim that $I_{S}=\bigcup_{t \geq S} M_{t}$, then $x \in M_{t}$ for some $t \geq S$.

It follows that $I_{A}(x) \geq t \geq S$ so that $x \in I_{S}$.

Conversely if $x \notin \bigcup_{t \geq S} M_{t}$, then $x \notin M_{t}$ for all $t \geq S$,

Which implies that $\mathrm{x} \notin \mathrm{M}_{\mathrm{t}}$ for all $\mathrm{t}>\mathrm{S}-\in$, that is if $\mathrm{x} \in \mathrm{M}_{\mathrm{t}}$ then $\mathrm{t} \in \mathrm{S}-\epsilon$.

Thus $\mathrm{I}_{\mathrm{A}}(\mathrm{x}) \leq \mathrm{S}-\in$ and so $\mathrm{x} \notin \mathrm{I}_{\mathrm{S}}$. Consequently $\mathrm{I}_{\mathrm{S}}=\bigcup_{\mathrm{t} \geq \mathrm{S}} \mathrm{M}_{\mathrm{t}}$

which is fuzzy equipotent lattice of L. This completes the proof.

Proposition : 3.5 : Let A be an IFS in L such that the nonempty upper and lower level sets $U\left(\mu_{A} ; t\right)$ and $L\left(\gamma_{A} ; t\right)$ of $A$ are equipotent lattices of $\mathrm{L}$ for every $\mathrm{t} \in[0,1]$. Then $\mathrm{A}$ is an intuitionistic fuzzy equipotent sub lattice of $\mathrm{L}$.

Proof : Let A be an IFS in a lattice L. For any $x, y \in U\left(\mu_{A} ; t\right)$ We have $\mu_{\mathrm{A}}(\mathrm{x}) \geq \mathrm{t}$ and $\mu_{\mathrm{A}}(\mathrm{y}) \geq \mathrm{t}$ and for $\mathrm{x}, \mathrm{y} \in \mathrm{L}\left(\gamma_{\mathrm{A}}\right.$; t), we have $\gamma_{A}(x) \leq t$,

$\gamma_{\mathrm{A}}(\mathrm{y}) \leq \mathrm{t}$. Now

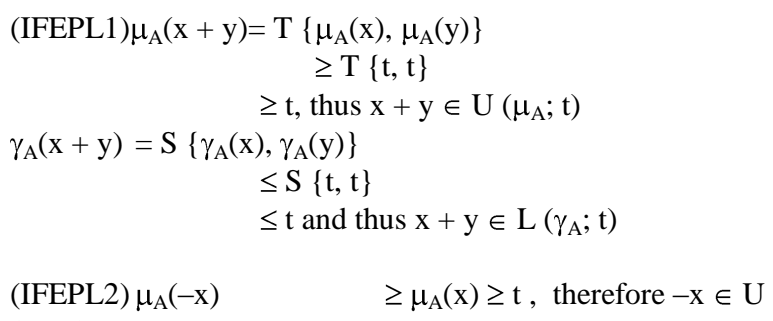

Hence $\mathrm{A}$ is an intuitionistic fuzzy equipotent lattice in $\mathrm{L}$. 
Proposition 3.6 : If IFS A in L is an intuitionistic fuzzy equipotent sub lattice then the non-empty upper and lower level sets $U\left(\mu_{A} ; t\right)$ and $L\left(\mu_{A} ; t\right)$ of $A$ are lattices of $L$ for every $t \in$ $[0,1]$.

Proof : Let $\mu$ be a fuzzy equipotent lattice of $\mathrm{L}$ and let $\mathrm{t} \in[0$, 1]. For any $x, y \in I_{A_{t}}$, we have

$$
\mathrm{I}_{\mathrm{A}}(\mathrm{x}+\mathrm{y}) \geq \mathrm{T}\left\{\mathrm{I}_{\mathrm{A}}(\mathrm{x}), \mathrm{I}_{\mathrm{A}}(\mathrm{y})\right\} \geq \mathrm{t}
$$

And so $x+y \in I_{A_{t}}$. Let $-x \in L$ and $x \in I_{A_{t}}$.

Then $I_{A}(-x) \geq I_{A}(x) \geq t$. Let $x, y \in L$ we have

$\mathrm{I}_{\mathrm{A}}(\mathrm{x} * \mathrm{y}) \geq \max \left\{\min \left\{\mathrm{I}_{\mathrm{A}}(\mathrm{x}), \mathrm{I}_{\mathrm{A}}(\mathrm{y})\right\}\right.$

$\geq \max \{\min \{\mathrm{t}, \mathrm{t}\}\}$

$\geq \mathrm{t}$, which shows that $\mathrm{x} * \mathrm{y} \in \mathrm{I}_{\mathrm{A}_{\mathrm{t}}}$

Conversely, assume that $I_{A_{t}}$ is a equipotent lattice of $L$ for

every $\mathrm{t} \in[0,1]$.

If $\mathrm{I}_{\mathrm{A}}\left(\mathrm{x}_{0}+\mathrm{y}_{0}\right)<\mathrm{T}\left\{\mathrm{I}_{\mathrm{A}}\left(\mathrm{x}_{0}\right), \mathrm{I}_{\mathrm{A}}\left(\mathrm{y}_{0}\right)\right\}$ for some $\mathrm{x}_{0}, \mathrm{y}_{0} \in \mathrm{L}$.

Then by taking

$$
\left.\mathrm{t}_{0}=\frac{1}{2}\left\{\mathrm{I}_{\mathrm{A}}\left(\mathrm{x}_{0}+\mathrm{y}_{0}\right)\right\}+\mathrm{T}\left\{\mathrm{I}_{\mathrm{A}}\left(\mathrm{x}_{0}\right), \mathrm{I}_{\mathrm{A}}\left(\mathrm{y}_{0}\right)\right\}\right\}
$$

We have $\left.\mathrm{I}_{\mathrm{A}}\left(\mathrm{x}_{0}+\mathrm{y}_{0}\right)\right\}<\mathrm{t}_{0}, \mathrm{I}_{\mathrm{A}}\left(\mathrm{x}_{0}\right)>\mathrm{t}_{0}$

$$
\begin{array}{ll}
\text { and } & \mathrm{I}_{\mathrm{A}}\left(\mathrm{y}_{0}\right)>\mathrm{t}_{0} \text {. Hence } \mathrm{x}_{0}+\mathrm{y}_{0} \notin \mathrm{I}_{\mathrm{A}_{\mathrm{t}_{0}}} \\
& \mathrm{x}_{0} \in \mathrm{I}_{\mathrm{A}_{\mathrm{t}_{0}}} \text { and } \quad \mathrm{y}_{0} \in \mathrm{I}_{\mathrm{A}_{\mathrm{t}_{0}}}
\end{array}
$$

This is a contradiction, and so $\mathrm{I}_{\mathrm{A}}(\mathrm{x}+\mathrm{y}) \geq \mathrm{T}\left\{\mathrm{I}_{\mathrm{A}}(\mathrm{x}), \mathrm{I}_{\mathrm{A}}(\mathrm{y})\right\}$, for all $\mathrm{x}, \mathrm{y} \in \mathrm{L}$.

Assume that $\mathrm{I}_{\mathrm{A}}\left(-\mathrm{x}_{0}\right)<\mathrm{I}_{\mathrm{A}}\left(\mathrm{x}_{0}\right)$ for some $\mathrm{x}_{0}, \mathrm{y}_{0} \in \mathrm{L}$.

Putting $\mathrm{M}_{0}=\frac{1}{2}\left\{\mathrm{I}_{\mathrm{A}}\left(-\mathrm{x}_{0}\right)+\mathrm{I}_{\mathrm{A}}\left(\mathrm{y}_{0}\right)\right\}$, then

$\mathrm{I}_{\mathrm{A}}\left(-\mathrm{x}_{0}\right)<\mathrm{M}_{0}<\mathrm{I}_{\mathrm{A}}\left(\mathrm{x}_{0}\right)$. It follows that $\mathrm{x}_{0} \in \mathrm{I}_{\mathrm{A}_{\mathrm{m}_{0}}}$ and $\quad-\mathrm{x}_{0}$ $\notin \mathrm{I}_{\mathrm{A}_{\mathrm{m}_{0}}}$ which is impossible.

Hence $I_{A}(-x) \geq I_{A}(x)$ for all $x, y \in L$. If the condition (ii) of the definition (2.8) is not true, then for fixed $\mathrm{P}_{0}=\frac{1}{2}\left\{\mathrm{I}_{\mathrm{A}}(\mathrm{x} * \mathrm{y})+\right.$ $\left.\mathrm{I}_{\mathrm{A}}(\mathrm{x})\right\}$

Then $\mathrm{I}_{\mathrm{A}}(\mathrm{x}+\mathrm{y}) \notin \mathrm{I}_{\mathrm{P}_{0}}$ and $\mathrm{x} \in \mathrm{I}_{\mathrm{P}_{0}}$ and $\mathrm{y} \in \mathrm{I}_{\mathrm{P}_{0}}$. This is a contradiction. Similarly we can show lower level set are lattice in $L$ for every $t \in[0,1]$.

Proposition 3.7 : If A is an intuitionistic fuzzy equipotent lattice of $\mathrm{L}$, then the sets

$\mathrm{L} \mu_{\mathrm{A}}=\left\{\mathrm{x} \in \mathrm{L} / \mu_{\mathrm{A}}(\mathrm{x})=\mu_{\mathrm{A}}(0)\right\}$ and

$\mathrm{L} \gamma_{\mathrm{A}}=\left\{\mathrm{x} \in \mathrm{L} / \gamma_{\mathrm{A}}(\mathrm{x})=\gamma_{\mathrm{A}}(0)\right\}$ are lattices of $\mathrm{L}$.
Proof : A be an intuitionistic fuzzy equipotent lattice and let $\mathrm{x}, \mathrm{y}$ $\in \mathrm{L} \mu_{\mathrm{A}}$

$$
\text { Then } \mathrm{I}_{\mathrm{A}}(\mathrm{x}+\mathrm{y}) \geq \mathrm{T}\left\{\mathrm{I}_{\mathrm{A}}(\mathrm{x}), \mathrm{I}_{\mathrm{A}}(\mathrm{y})\right\}=\mathrm{I}_{\mathrm{A}}(0) \text {. }
$$

and so, $\mathrm{I}_{\mathrm{A}}(\mathrm{x}+\mathrm{y})=\mathrm{I}_{\mathrm{A}}(0)$ or $\mathrm{x}+\mathrm{y} \in \mathrm{L} \mu_{\mathrm{A}}$.

For every $-x \in L$ and $x \in L \mu_{A}$, we have

$\mathrm{I}_{\mathrm{A}}(-\mathrm{x}) \geq \mathrm{I}_{\mathrm{A}}(\mathrm{x})=\mathrm{I}_{\mathrm{A}}(0)$. Hence $-\mathrm{x} \in \mathrm{L} \mu_{\mathrm{A}}$, which shows that $\mathrm{L} \mu_{\mathrm{A}}$ is a negative of $\mathrm{L}$.

Let $\mathrm{x}, \mathrm{y} \in \mathrm{L} \mu_{\mathrm{A}}$ and hence

$\mathrm{I}_{\mathrm{A}}(\mathrm{x} * \mathrm{y}) \geq \max \left\{\min \left\{\mathrm{I}_{\mathrm{A}}(\mathrm{x}), \mathrm{I}_{\mathrm{A}}(\mathrm{y})\right\}\right\}$

$\geq \max \left\{\min \left\{\mathrm{I}_{\mathrm{A}}(0), \mathrm{I}_{\mathrm{A}}(0)\right\}\right\}$

$$
=\mathrm{I}_{\mathrm{A}}(0) \text {. }
$$

Therefore $\mathrm{L} \mu_{\mathrm{A}}$ is a lattice of L. Similarly, we can show the complement of $\mu_{\mathrm{A}}$.

Proposition 3.8 : Let A be a self-distributive intuitionistic fuzzy sets in $L$. Then the IFS $I_{a}{ }^{b}$ in $L$ is intuitionistic equipotent fuzzy sublattice of $\mathrm{L}$ for all $\mathrm{a}, \mathrm{b} \in \mathrm{L}$.

Proof : Since A be self distributive intuitionistic fuzzy sets in $\mathrm{L}$ and $\mathrm{I}_{\mathrm{A}}$ is fuzzy equipotent lattice (ie) $\mathrm{I}_{\mathrm{a}}^{\mathrm{b}}(\mathrm{x})=\mathrm{a}^{\mathrm{b}} \mathrm{I}(\mathrm{x})$, for any $\mathrm{a}, \mathrm{b}$ $\in \mathrm{L}$.

$$
\begin{aligned}
& \text { (IFEPL1) } \mathrm{I}_{\mathrm{a}}^{\mathrm{b}}(\mathrm{x}+\mathrm{y})=\mathrm{a}^{\mathrm{b}} \mathrm{I}(\mathrm{x}+\mathrm{y}) \\
& \geq \mathrm{T}\left\{\mathrm{a}^{\mathrm{b}} \mathrm{I}(\mathrm{x}), \mathrm{a}^{\mathrm{b}} \mathrm{I}(\mathrm{y})\right\} \\
& \geq \mathrm{T}\left\{\mathrm{I}_{\mathrm{a}}{ }^{\mathrm{b}}(\mathrm{x}), \mathrm{I}_{\mathrm{a}}^{\mathrm{b}}(\mathrm{y})\right\} \\
& \text { (IFEPL2) } \mathrm{I}_{\mathrm{a}}^{\mathrm{b}}(-\mathrm{x})=\mathrm{a}^{\mathrm{b}} \mathrm{I}(-\mathrm{x}) \\
& \geq \mathrm{a}^{\mathrm{b}} \mathrm{I}(\mathrm{x}) \\
& \geq \mathrm{I}_{\mathrm{a}}^{\mathrm{b}}(\mathrm{x}) \\
& \text { (IFEPL3) } \mathrm{I}_{\mathrm{a}}^{\mathrm{b}}(\mathrm{x} * \mathrm{y})=\mathrm{a}^{\mathrm{b}} \mathrm{I}(\mathrm{x} * \mathrm{y}) \\
& \geq \mathrm{a}^{\mathrm{b}} \max \{\min \{\mathrm{I}(\mathrm{x}), \mathrm{I}(\mathrm{y})\} \\
& \geq \max \left\{\min \left\{\mathrm{a}^{\mathrm{b}} \mathrm{I}(\mathrm{x}), \mathrm{a}^{\mathrm{b}} \mathrm{I}(\mathrm{y})\right\}\right. \\
& \geq \max \left\{\min \left\{\mathrm{I}_{\mathrm{a}}^{\mathrm{b}}(\mathrm{x}), \mathrm{I}_{\mathrm{a}}^{\mathrm{b}}(\mathrm{y})\right\}\right.
\end{aligned}
$$

Hence $\mathrm{I}_{\mathrm{a}}{ }^{\mathrm{b}}$ is intuitionistic fuzzy equipotent lattice in $\mathrm{L}$.

Proposition 3.9 : Let L be a lattice and I be a sub set of L. If I is an intuitionistic equipotent fuzzy sub lattice of $\mathrm{L}$, then the characteristic function $\psi_{\mathrm{I}}$ of $\mathrm{I}$ is a intuitionistic equipotent fuzzy sublattices with respect to $S$.

Proof : Since $\mathrm{L}$ be a lattice and $\mathrm{I} \subset \mathrm{L}$. The characteristic function of $\mathrm{I}$ is $\psi_{\mathrm{I}}: \mathrm{L} \rightarrow[0,1]$. I is intuitionistic equipotent fuzzy sub lattice of $\mathrm{L}$.

Claim : $\psi_{\mathrm{I}}$ is intuitionistic equipotent fuzzy sublattice of L. for any $\mathrm{x}, \mathrm{y} \in \mathrm{L}$.

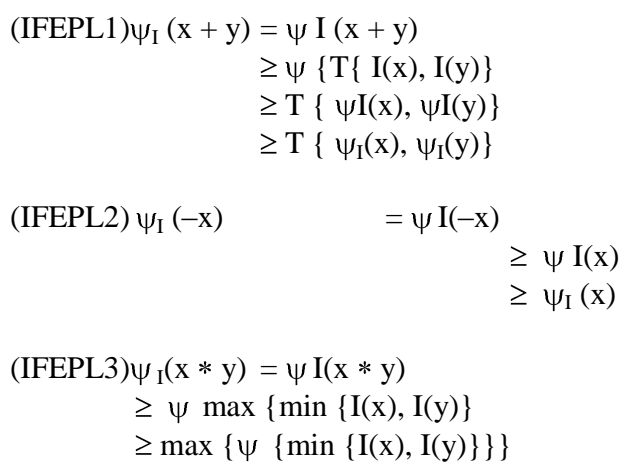




\begin{abstract}
$\geq \max \{\min \{\psi \mathrm{I}(\mathrm{x}), \psi \mathrm{I}(\mathrm{y})\}\}$
$\geq \max \left\{\min \left\{\psi_{\mathrm{I}}(\mathrm{x}), \psi_{\mathrm{I}}(\mathrm{y})\right\}\right\}$
\end{abstract}

$\therefore \psi_{\mathrm{I}}$ is fuzzy equipotent sub lattice of $\mathrm{L}$.

Proposition 3.10 : Let $S$ be a $S$ norm and $\mu, \gamma$ be a two intuitionistic equipotent sublattice of $L$ with respect to $S$. If $S^{*}$ dominates $S$, then $S *$-product, $[\mu, \gamma]_{S^{*}}$ of $\mu$ and $\gamma$ is intuitionistic equipotent fuzzy sub lattice of $\mathrm{L}$.

Proof : $\mu$ and $\gamma$ be two intuitionistic fuzzy equipotent sub lattice of $\mathrm{L}$ with respect to $\mathrm{S}$-norms. Since $\mathrm{S}^{*}$ dominates the norm $\mathrm{S}$.

Claim : $\mathrm{S}^{*}$ - product forms intuitionistic fuzzy equipotent sub lattice of $\mathrm{L}$.

$($ IFEPL1 $)[\mu \cdot \gamma]_{S^{*}}(\mathrm{x}+\mathrm{y})$

$=\max \left\{\mu_{\mathrm{S}^{*}}(\mathrm{x}+\mathrm{y}), \gamma_{\mathrm{S}^{*}}(\mathrm{x}+\mathrm{y})\right\}$

$\geq \max \left\{\mathrm{S}^{*} \mu(\mathrm{x}+\mathrm{y}), \mathrm{S}^{*} \gamma(\mathrm{x}+\mathrm{y})\right\}$

$\geq \max \left\{\mathrm{S}^{*} \mathrm{~T}\{\mu(\mathrm{x}), \mu(\mathrm{y})\}\right.$,

$\mathrm{S}^{*} \mathrm{~T}\{\gamma(\mathrm{x}), \gamma(\mathrm{y})\}$

$\geq \max \left\{\mathrm{T}\left\{\mathrm{S}^{*}\{\mu(\mathrm{x}), \gamma(\mathrm{x})\}, \mathrm{S}^{*}\{\mu(\mathrm{y}), \gamma(\mathrm{y})\}\right\}\right.$

$\geq \mathrm{T}\left\{\max \left\{\mu_{\mathrm{S}^{*}}(\mathrm{x}), \gamma_{\mathrm{S}^{*}}(\mathrm{x}), \mu_{\mathrm{S}^{*}}(\mathrm{y}), \quad \gamma_{\mathrm{S}^{*}}(\mathrm{y})\right\}\right\}$

$\geq \mathrm{T}\left\{\max \left\{\mu_{\mathrm{S}^{*}}(\mathrm{x}), \gamma_{\mathrm{S}^{*}}(\mathrm{x})\right\}, \quad \max \left\{\mu_{\mathrm{S}^{*}}(\mathrm{y}), \gamma_{\mathrm{S}^{*}}\right.\right.$

(y) $\}\}$

$\left.\geq \mathrm{T}\left\{[\mu \cdot \gamma]_{\mathrm{S}^{*}}(\mathrm{x}),[\mu \cdot \gamma]_{\mathrm{S}^{*}}(\mathrm{y})\right\}\right\}$

(IFEPL2) $[\mu \cdot \gamma]_{S^{*}}(-\mathrm{x})$

$=\max \left\{\mu_{\mathrm{S}^{*}}(-\mathrm{x}), \gamma_{\mathrm{S}^{*}}(-\mathrm{x}\}\right.$

$\geq \max \left\{\mathrm{S}^{*} \mu(-\mathrm{x}), \mathrm{S}^{*} \gamma(-\mathrm{x})\right\}$

$\geq \max \left\{\mathrm{S}^{*} \mu(\mathrm{x}), \mathrm{S}^{*} \gamma(\mathrm{x})\right\}$

$\geq \max \left\{\mu_{\mathrm{S}^{*}}(\mathrm{x}), \gamma_{\mathrm{S}^{*}}(\mathrm{x})\right\}$

$\geq[\mu, \gamma]_{S^{*}}(\mathrm{x})$

(IFEPL3) $[\mu \cdot \gamma]_{S^{*}}(\mathrm{x} * \mathrm{y})$

$=\max \left\{\mu_{\mathrm{S}^{*}}(\mathrm{x} * \mathrm{y}), \gamma_{\mathrm{S}^{*}}(\mathrm{x} * \mathrm{y})\right\}$

$\geq \max \left\{S^{*} \mu(x * y), S^{*} \gamma(x * y)\right\}$

$\geq \max \left\{S^{*}\{\max \{\min \{\mu(\mathrm{x}), \mu(\mathrm{y})\}\}\right.$

$\geq \max \left\{\min \left\{\max \left\{\mathrm{S}^{*} \mu(\mathrm{x}), \mathrm{S}^{*} \mu(\mathrm{y})\right\}\right\} \geq \max \left\{\min \left\{\max \left\{\mathrm{S}^{*} \mu\right.\right.\right.\right.$

$\left.\left.(\mathrm{x}), \mathrm{S}^{*} \mu(\mathrm{y})\right\}\right\}$

$\left.\left.\max \left\{\mathrm{S}^{*} \gamma(\mathrm{x}), \mathrm{S}^{*} \gamma(\mathrm{y})\right\}\right\}\right\}$

$\geq \max \left\{\min \left\{\max \left\{\mu_{\mathrm{S}^{*}}(\mathrm{x}), \gamma_{\mathrm{S}^{*}}(\mathrm{x})\right\}\right.\right.$,

$\left.\left.\max \left\{\mu_{\mathrm{S}^{*}}(\mathrm{y}), \gamma_{\mathrm{S}^{*}}(\mathrm{y})\right\}\right\}\right\}$

$\geq \max \left\{\min \left\{[\mu \cdot \gamma]_{\mathrm{S}^{*}}(\mathrm{x}),[\mu \cdot \gamma]_{\mathrm{S}^{*}}(\mathrm{y})\right\}\right\}$

$\therefore[\mu, \gamma]_{S^{*}}(\mathrm{x} * \mathrm{y})$

$\geq \max \left\{\min \left\{[\mu \cdot \gamma]_{S^{*}}(x),[\mu \cdot \gamma]_{S^{*}}(y)\right\}\right\}$,

$\geq \max \left\{\min \left\{\max \left\{\mathrm{S}^{*} \mu(\mathrm{x}), \mathrm{S}^{*} \mu(\mathrm{y})\right\}\right\}\right.$

$\left.\left.\max \left\{\mathrm{S}^{*} \gamma(\mathrm{x}), \mathrm{S}^{*} \gamma(\mathrm{y})\right\}\right\}\right\}$

$\geq \max \left\{\min \left\{\max \left\{\mu_{\mathrm{S}^{*}}(\mathrm{x}), \gamma_{\mathrm{S}^{*}}(\mathrm{x})\right\}\right.\right.$,

$\left.\left.\max \left\{\mu_{\mathrm{S}^{*}}(\mathrm{y}), \gamma_{\mathrm{S}^{*}}(\mathrm{y})\right\}\right\}\right\}$

$\geq \max \left\{\min \left\{[\mu \cdot \gamma]_{S^{*}}(\mathrm{x}),[\mu \cdot \gamma]_{\mathrm{S}^{*}}(\mathrm{y})\right\}\right\}$

$\therefore[\mu \cdot \gamma]_{S^{*}}(\mathrm{x} * \mathrm{y}) \geq \max \left\{\min \left\{[\mu \cdot \gamma]_{S^{*}}(\mathrm{x}),[\mu \cdot \gamma]_{S^{*}}(\mathrm{y})\right\}\right\}$,

If $\geq \max \left\{\min \left\{\max \left\{\mathrm{S}^{*} \mu(\mathrm{x}), \mathrm{S}^{*} \mu(\mathrm{y})\right\}\right\}\right.$

$\left.\left.\max \left\{S^{*} \gamma(\mathrm{x}), \mathrm{S}^{*} \gamma(\mathrm{y})\right\}\right\}\right\} \geq \max \left\{\min \left\{\max \left\{\mu_{\mathrm{S}^{*}}(\mathrm{x}), \gamma_{\mathrm{S}^{*}}(\mathrm{x})\right\}\right.\right.$, $\left.\left.\max \left\{\mu_{\mathrm{S}^{*}}(\mathrm{y}), \gamma_{\mathrm{S}^{*}}(\mathrm{y})\right\}\right\}\right\}$

$\geq \max \left\{\min \left\{[\mu \cdot \gamma]_{S^{*}}(\mathrm{x}),[\mu \cdot \gamma]_{S^{*}}(\mathrm{y})\right\}\right\}$

$\therefore[\mu \cdot \gamma]_{S^{*}}(\mathrm{x} * \mathrm{y}) \geq \max \left\{\min \left\{[\mu \cdot \gamma]_{\mathrm{S}^{*}}(\mathrm{x}),[\mu \cdot \gamma]_{\mathrm{S}^{*}}(\mathrm{y})\right\}\right\}$, If

$\mathrm{S} *$ dominates $\mathrm{S}$
Proposition : 3.11 : Let $\mathrm{f}: \mathrm{R} \rightarrow \mathrm{R}^{\prime}$ be a homomorphism of $\mathrm{R}$ and $R^{\prime}$. If $\mu$ and $\gamma$ are two intuitionistic fuzzy equipotent sub lattice of $L^{\prime}$ with respect to $S$ then $f^{-1}\left([\mu, \gamma]_{S^{*}}\right)$ is intuitionistic fuzzy equipotent sub lattice of $\mathrm{L}$ with respect to $\mathrm{S}$.

Proof : A mapping $\mathrm{f}: \mathrm{R} \rightarrow \mathrm{R}^{\prime}$ be a homomorphism $\mu$ and $\gamma$ are intuitionistic equipotent fuzzy sub lattice of $\mathrm{L}^{\prime}$ with respect to $S$. Since $\mathrm{S}^{*}$ dominates $\mathrm{S}$. We have $\mathrm{S}^{*} \supseteq \mathrm{S}$.

Claim : $\mathrm{f}^{-1}\left([\mu \cdot \gamma]_{\mathrm{S}^{*}}\right)$ is intuitionistic fuzzy equipotent sub lattice of $L$ with respect to $S$.

$($ IFEPL1 $) \mathrm{f}^{-1}\left([\mu \cdot \gamma]_{S^{*}}\right)(\mathrm{x}+\mathrm{y})=[\mu \cdot \gamma]_{S^{*}} \mathrm{f}(\mathrm{x}+\mathrm{y})$

$=[\mu \cdot \gamma]_{S^{*}}\{\mathrm{f}(\mathrm{x})+\mathrm{f}(\mathrm{y})\}$

$=\max \left\{\mu_{\mathrm{S}^{*}}(\mathrm{f}(\mathrm{x})+\mathrm{f}(\mathrm{y})), \gamma_{\mathrm{S}^{*}}(\mathrm{f}(\mathrm{x})+\mathrm{f}(\mathrm{y}))\right\}$

$=\max \left\{\mathrm{S}^{*} \mu(\mathrm{f}(\mathrm{x})+\mathrm{f}(\mathrm{y})), \mathrm{S}^{*} \gamma(\mathrm{f}(\mathrm{x})+\mathrm{f}(\mathrm{y}))\right\}$

$\geq \mathrm{T}\left\{\max \left\{\mathrm{S}^{*}(\mu \mathrm{f}(\mathrm{x}), \mu \mathrm{f}(\mathrm{y})), \mathrm{S}^{*}(\gamma \mathrm{f}(\mathrm{x}), \gamma \mathrm{f}(\mathrm{y}))\right\}\right.$

$\geq \mathrm{T}\left\{\max \left(\mu_{\mathrm{S}^{*}} \mathrm{f}(\mathrm{x}), \mu_{\mathrm{S}^{*}} \mathrm{f}(\mathrm{y})\right)\right.$,

$\left.\max \left(\gamma_{\mathrm{S}^{*}} \mathrm{f}(\mathrm{x}), \gamma_{\mathrm{S}^{*}} \mathrm{f}(\mathrm{y})\right)\right\}$

$\geq \mathrm{T}\left\{\max \left(\mathrm{f}^{-1} \mu_{\mathrm{S}^{*}}(\mathrm{x}), \mathrm{f}^{-1} \gamma_{\mathrm{S}^{*}}(\mathrm{x})\right)\right.$,

$\left.\max \left(\mathrm{f}^{-1} \mu_{\mathrm{S}^{*}}(\mathrm{y}), \mathrm{f}^{-1} \gamma_{\mathrm{S}^{*}}(\mathrm{y})\right)\right\}$

$\left.\geq \mathrm{T}\left\{\mathrm{f}^{-1}[\mu \cdot \gamma]_{\mathrm{S}^{*}}(\mathrm{x}), \mathrm{f}^{-1}[\mu \cdot \gamma]_{\mathrm{S}^{*}}(\mathrm{y})\right\}\right\}$

$\left(\right.$ IFEPL2) $\mathrm{f}^{-1}\left([\mu \cdot \gamma]_{S^{*}}\right)(-\mathrm{x})=[\mu \cdot \gamma]_{\mathrm{S}^{*}} \mathrm{f}(-\mathrm{x})$

$=\max \left\{\mu_{\mathrm{S}^{*}}\left(\mathrm{f}(-\mathrm{x}), \gamma_{\mathrm{S}^{*}}(\mathrm{f}(-\mathrm{x})\}\right.\right.$

$=\max \left\{\mathrm{f}^{-1} \mu_{\mathrm{S}^{*}}(-\mathrm{x}), \mathrm{f}^{-1} \gamma_{\mathrm{S}^{*}}(-\mathrm{x})\right\}$

$=\max \left\{\mathrm{f}^{-1} \mathrm{~S}^{*} \mu(-\mathrm{x}), \mathrm{f}^{-1} \mathrm{~S}^{*} \gamma(-\mathrm{x})\right\}$

$\geq \max \left\{\mathrm{f}^{-1} \mathrm{~S}^{*} \mu(\mathrm{x}), \mathrm{f}^{-1} \mathrm{~S}^{*} \gamma(\mathrm{x})\right\}$

$\geq \max \left\{\mathrm{f}^{-1} \mu_{\mathrm{S}^{*}}(\mathrm{x}), \mathrm{f}^{-1} \gamma_{\mathrm{S}^{*}}(\mathrm{x})\right\}$

$\geq \mathrm{f}^{-1}[\mu, \gamma]_{S^{*}}(\mathrm{x})$

$($ IFEPL3 $) f^{-1}\left([\mu \cdot \gamma]_{S^{*}}\right)(x * y)=[\mu \cdot \gamma]_{S^{*}} f(x * y)$

$=[\mu \cdot \gamma]_{S^{*}}\{\mathrm{f}(\mathrm{x}) * \mathrm{f}(\mathrm{y})\}$

$=\max \left\{\mu_{\mathrm{S}^{*}}(\mathrm{f}(\mathrm{x}) * \mathrm{f}(\mathrm{y})), \gamma_{\mathrm{S}^{*}}(\mathrm{f}(\mathrm{x}) * \mathrm{f}(\mathrm{y}))\right\}$

$=\max \{\mathrm{S} * \mu(\mathrm{f}(\mathrm{x}) * \mathrm{f}(\mathrm{y})), \mathrm{S} * \gamma(\mathrm{f}(\mathrm{x}) * \mathrm{f}(\mathrm{y}))\}$

$\geq \max \left\{\max \left\{\min \left\{\mathrm{S}^{*}(\mu \mathrm{f}(\mathrm{x}), \mu \mathrm{f}(\mathrm{y}))\right\}\right\}\right.$,

$\left.\max \left\{\min \left\{\mathrm{S}^{*}(\gamma \mathrm{f}(\mathrm{x}), \gamma \mathrm{f}(\mathrm{y}))\right\}\right\}\right\}$

$\geq \max \left\{\min \left\{\max \left\{\mu_{\mathrm{S}^{*}} \mathrm{f}(\mathrm{x}), \mu_{\mathrm{S} *} \mathrm{f}(\mathrm{y})\right\}\right.\right.$,

$\left.\left\{\max \left\{\gamma_{\mathrm{S}^{*}} \mathrm{f}(\mathrm{x}), \gamma_{\mathrm{S} *} \mathrm{f}(\mathrm{y})\right\}\right\}\right\}$

$\geq \max \left\{\min \left\{\max \left\{\mu_{\mathrm{S}^{*}} \mathrm{f}(\mathrm{x}), \gamma_{\mathrm{S}^{*}} \mathrm{f}(\mathrm{x})\right\}\right.\right.$,

$\left.\left\{\max \left\{\mu_{\mathrm{S}^{*}} \mathrm{f}(\mathrm{y}), \gamma_{\mathrm{S}^{*}} \mathrm{f}(\mathrm{y})\right\}\right\}\right\}$

$\geq \max \left\{\min \left\{\max \left\{\mathrm{f}^{-1} \mu_{\mathrm{S}^{*}}(\mathrm{x}), \mathrm{f}^{-1} \gamma_{\mathrm{S}^{*}}(\mathrm{x})\right\},\left\{\max \left\{\mathrm{f}^{-1} \mu_{\mathrm{S}^{*}}(\mathrm{y})\right.\right.\right.\right.$,

$\left.\left.\left.\mathrm{f}^{-1} \gamma_{\mathrm{S}^{*}}(\mathrm{y})\right\}\right\}\right\}$

$\geq \max \left\{\min \left\{\mathrm{f}^{-1}\left([\mu \cdot \gamma]_{\mathrm{S}^{*}}(\mathrm{x}), \quad \mathrm{f}^{-1}\left([\mu \cdot \gamma]_{\mathrm{S}^{*}}(\mathrm{y})\right)\right\}\right.\right.$

Therefore $\mathrm{f}^{-1}\left(\left([\mu, \gamma]_{S^{*}}\right)\right.$ is intuitionistic fuzzy equipotent sub lattice of $\mathrm{L}$ under the domination of $\mathrm{S}^{*}$.

Proposition 3.12 : A lattice homomorphic image of intuitionistic fuzzy equipotent sub lattice of $\mathrm{L}$ with sup property is intuitionistic fuzzy equipotent sub lattice.

\section{Proof :}

Let $f: L \rightarrow L^{\prime}$ be lattice homorphism of $L$ and let $\mathrm{I}_{\mathrm{A}}$ be fuzzy equipotent lattice of $\mathrm{L}$ with sup property. such that 


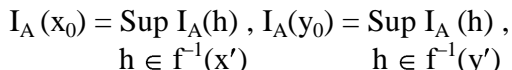

$$
\begin{aligned}
& \text { Then we can deduce that } \\
& \begin{array}{r}
\left(\text { IFEPL1) } \mathrm{I}_{\mathrm{A}}^{\mathrm{f}}\left(\mathrm{x}^{\prime}+\mathrm{y}^{\prime}\right) \quad=\operatorname{Sup~}_{\mathrm{A}}(\mathrm{z})\right. \\
\mathrm{z} \in \mathrm{f}^{-1}\left(\mathrm{x}^{\prime}+\mathrm{y}^{\prime}\right)
\end{array} \\
& \geq \mathrm{T}\left\{\mathrm{I}_{\mathrm{A}}\left(\mathrm{x}_{0}\right), \mathrm{I}_{\mathrm{A}}\left(\mathrm{y}_{0}\right)\right\} \\
& \geq \mathrm{T}\left\{\operatorname{Sup} \mathrm{I}_{\mathrm{A}}(\mathrm{h}), \quad \operatorname{Sup} \mathrm{I}_{\mathrm{A}}(\mathrm{h})\right\} \\
& h \in \mathrm{f}^{-1}\left(\mathrm{x}^{\prime}\right) \quad \mathrm{h} \in \mathrm{f}^{-1}\left(\mathrm{y}^{\prime}\right) \\
& \geq \mathrm{T}\left\{\mathrm{I}_{\mathrm{A}}^{\mathrm{f}}\left(\mathrm{x}^{\prime}\right), \mathrm{I}_{\mathrm{A}}^{\mathrm{f}}\left(\mathrm{y}^{\prime}\right)\right\} \text {, for all } \mathrm{x}, \mathrm{y} \in \mathrm{L} \text {. } \\
& \text { (IFEPL2) } \mathrm{I}_{\mathrm{A}}^{\mathrm{f}}\left(-\mathrm{x}^{\prime}\right)=\operatorname{Sup~}_{\mathrm{A}}(\mathrm{z}) \text {, } \\
& \mathrm{z} \in \mathrm{f}^{-1}\left(-\mathrm{x}^{\prime}\right) \\
& \geq \mathrm{I}_{\mathrm{A}}\left(\mathrm{x}_{0}\right) \\
& \geq \quad \operatorname{Sup} \mathrm{I}_{\mathrm{A}}(\mathrm{h}) \\
& \mathrm{h} \in \mathrm{f}^{-1}\left(\mathrm{x}^{\prime}\right) \\
& \geq \mathrm{I}_{\mathrm{A}}^{\mathrm{f}}(\mathrm{x})
\end{aligned}
$$

$$
\begin{aligned}
& \left(\text { IFEPL3) } \mathrm{I}_{\mathrm{A}}^{\mathrm{f}}\left(\mathrm{x}^{\prime} * \mathrm{y}^{\prime}\right) \quad=\operatorname{Sup~}_{\mathrm{A}}(\mathrm{z}),\right. \\
& \mathrm{z} \in \mathrm{f}^{-1}\left(\mathrm{x}^{\prime} * \mathrm{y}^{\prime}\right) \\
& \geq \max \left\{\min \left\{\mathrm{I}_{\mathrm{A}}\left(\mathrm{x}_{0}\right), \mathrm{I}_{\mathrm{A}}\left(\mathrm{y}_{0}\right)\right\}\right\} \\
& \geq \max \left\{\min \left\{\operatorname{Sup} \mathrm{I}_{\mathrm{A}}(\mathrm{h}), \quad \operatorname{Sup~}_{\mathrm{A}}(\mathrm{h})\right\}\right. \\
& \geq \max \left\{\min \left\{\mathrm{I}_{\mathrm{A}}^{\mathrm{f}}\left(\mathrm{x}^{\prime}\right), \mathrm{I}_{\mathrm{A}}^{\mathrm{f}}\left(\mathrm{y}^{\prime}\right)\right\}, \text { for all } \mathrm{x}, \mathrm{y} \in \mathrm{L} .\right.
\end{aligned}
$$

Hence, lattice homomorphic image of equipotent fuzzy lattice with sup-property forms intuitionistic equipotent fuzzy sub lattice on $\mathrm{L}$.

\section{APPLICATIONS}

Lattice structure has been found to be extremely important in the areas of quantum logic Erogodic theory, Reynold's operations, Soft Computing, Communication system, Information analysis system, artificial intelligences and physical science.

\section{CONCLUSIONS}

Bustince and Burillo introduced the concept of intuitionistic fuzzy relations and investigated some of its properties and Yon and Kim introduced the notion of intuitionistic fuzzy sublattices, filters and ideals. In this paper, the notion of fuzzy equipotent lattice relation on the family of all intuitionistic fuzzy sub lattices of $\mathrm{L}$ are discussed.

\section{REFERENCES}

[1] K. Atanassov, Intuitionistic fuzzy sets, Fuzzy sets and systems, 20 (1986), pp. 87-96.

[2] N. Ajmal, the lattice of fuzzy normal sub groups is modular, Inform. Sci. 83 (1995), pp. 199-209.

[3] N. Ajmal and K.V. Thomas, The lattice of fuzzy subgroups and fuzzy normal sub-groups, Inform. Sci., 76 (1994), pp. $1-11$.

[4] N. Ajmal and K.V. Thomas, A complete study of the lattices of fuzzy congruence and fuzzy normal sub groups, Inform. Sci. 82 (1995), pp. 198-218.

[5] B. Banerjee and D.Kr. Basnet, Intuitionstic fuzzy sub rings and ideals, J. Fuzzy Math. 11 (1) (2003), pp. 139-155.

[6] R. Biswas, Insuitionstic fuzzy subrings, Mathematical Forum x(1989), pp. 37-46.

[7] H. Bustince and P. Butillo, Structures on intuitionistic fuzzy relations, Fuzzy sets and systems 78 (1996), pp. 293 -303 .

[8] D. Coker and A. Hayder Es, On fuzzy compactness in intuitionistic fuzzy topological spaces, J. Fuzzy Math. 3 (1995), $899-909$

[9] D. Coker. An introduction to intuitionistic fuzzy topological spaces, Fuzzy sets and systems 88 (1997), pp. $81-89$.

[10] J.A. Goguen, L-fuzzy sets, J. Math Anal. Appl 18, pp. 145 174 (1967).

[11] H. Gurcay, D. Coker and A. Haydar Es, on fuzzy continuity in intuitionistic fuzzy topological spaces, J. fuzzy Maths. 5 (1997), pp. 365-378.

[12] K. Hur, S.Y. Jang and H.Kl. Kang, Intuitionistic fuzzy sub groupoids, International Journal of Fuzzy Logic and Intelligent systems 3 (1) (2003), 72-77.

[13] K. Hur, H.W. Kang and H.K. Song, Intuitionistic fuzzy sub groups and sub rings, Honam Math. J. 25 (1) (2003), pp. $19-41$.

[14] K. Har, S.Y. Jang and H.W. Kang, Intuitionistic fuzzy sub groups and Cosets, Honam Math. J. 26 (1) (2004), pp. 1741.

[15] K. Hur, Y.B. Jun and J.H. Ryou, Intuitionistic fuzzy topological groups, Honam Math. J. 26 (2) (2004), pp. 163 192.

[16] S.J. Lee and E.P. Lee, The categoris of Intuitionistic fuzzy topological spaces, Bull. Korean Math Soc. 37 (1) (2000), pp. 63-76.

[17] T.K. Mukharjee and M.K. Sen, on fuzzy ideals of a ring 1 , Fuzzy sets and systems 21 (1987), pp. $98-104$.

[18] M. Marudai and V. Rajendran, Characterization of fuzzy lattices on a group with respect to T-norms, International Journal of Computer Applications. (0975-8887) Volume 8 - No.8, October 2010. pp. 8 - 15 . 
[19] M. Marudai and V. Rajendran, Generalized product of fuzzy lattices and fuzzy ideals, Advances in Fuzzy Mathematics, (ISSN 0973-533x) Volume 6, Number 1 (2011), pp. 135 - 144.

[20] Nanda. S, Fuzzy Lattices, Bulletin of Calcutta Math. Soc. 18 (1989), pp.1 - 2 .

[21] A. Rosenfeld, Fuzzy groups, J. Math. Anal. Appl. 35 (1971), pp. $512-517$

[22] G.S.V. Satya Saibaba, Fuzzy lattice ordered groups, South East Asian Bulletin of Mathamatics 32, pp. $749-766$ (2008).
[23] K.V. Thomas and Latha. S. Nair, Rough ideals in a lattice, International Journal fuzzy systems and rough systems. (To appear).

[24] K.V. Thomas and Latha. S. Nair, Rough intuitionistic fuzzy sets in a lattice, International Mathematical forum, Vol.6, 2011, No.27, pp. $1327-1335$.

[25] Wang-Jin Liu, Fuzzy invariant sub groups and fuzzy ideals, Fuzzy sets and systems 8 (1982), pp. $133-139$.

[26] Y.H. Yon and K.H. Kim, on intuitionistic fuzzy filters and ideals of lattices, Fat East J. Math, Sci 1(3), pp. 429 - 442.

[27] L.A. Zadeh, Fuzzy sets, Inform and control 8 (1965), pp. $338-353$ 